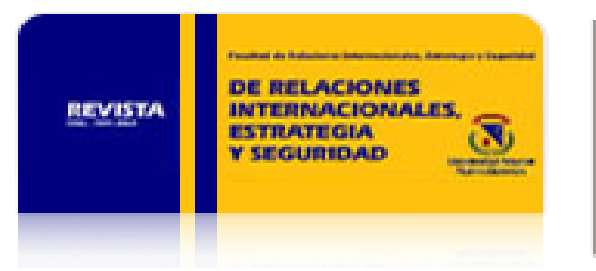

Revista de Relaciones Internacionales, Estrategia y Seguridad

ISSN: 1909-3063

cinuv.relinternal@unimilitar.edu.co

Universidad Militar Nueva Granada

Colombia

Cadena Montenegro, José Luis

La geopolítica y los delirios imperiales de la expansión territorial a la conquista de mercados Revista de Relaciones Internacionales, Estrategia y Seguridad, vol. 1, núm. 1, enero-junio, 2006, pp.

115-141

Universidad Militar Nueva Granada

Bogotá, Colombia

Disponible en: http://www.redalyc.org/articulo.oa?id=92710107

- Cómo citar el artículo

- Número completo

- Más información del artículo

- Página de la revista en redalyc.org

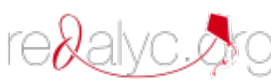

Sistema de Información Científica

Red de Revistas Científicas de América Latina, el Caribe, España y Portugal

Proyecto académico sin fines de lucro, desarrollado bajo la iniciativa de acceso abierto 


\title{
La geopolítica y los delirios imperiales de la expansión territorial a la conquista de mercados
}

\author{
José Luis Cadena Montenegro ${ }^{1}$
}

\section{Resumen}

Este artículo está orientado a explicar de manera breve, el concepto Geopolítica, su origen, desarrollo, escuelas e impacto a principios del siglo XX. Se pretende que cualquier lector desprevenido, sin mayores conocimientos geográficos, encuentre la importancia de esta nueva ciencia en la vida de las naciones. El proceso de globalización está permitiendo que la teoría sobre la supervivencia de los estados, altere de manera especial, las relaciones económicas y las anteponga a los intereses políticos. La acumulación de grandes capitales por compañías transnacionales, también parece hoy, una nueva forma de hacer geopolítica. Este artículo forma parte de una investigación de alcance mayor, sobre las nuevas prácticas de esta ciencia que se encuentran en pleno desarrollo al inicio del siglo XXI.

Palabras clave: geopolítica, territorio, espacio, estrategia, imperio, ideología.

Geógrafo y politólogo, profesional en Ciencias Militares, magíster en Ciencia Política, Universidad de los Andes; magíster en Planeación Socioeconómica, Universidad Santo Tomás; magíster en Geografía y Ordenamiento Territorial, convenio UPTC-ICAC. Doctor en Geografía, especialidad en Geopolítica, Universidad Nacional Autónoma de México. Catedrático universitario, consultor internacional en Defensa y Seguridad. Jlcadenam@yahoo.com. 
REVISTA DE RELACIONES INTERNACIONALES, ESTRATEGIA Y SEGURIDAD

\begin{abstract}
This article introduces the concept of Geopolitics through a brief discussion on the origen, schools of thought, development, and impact of this new science in the beginning of the 20th Century. The author strives to create an awareness for the importance of Geopolitics in the livelihood of nation-states using concise language for readers without prior geographical knowledge. The process of globalization combined with the accumulation of large sums of capital by transnational enterprises has allowed for the theory of the survival of states to be altered, placing economic relationships before political interests. This could present a new form of Geopolitics. This document forms part of an ongoing research effort that aims to identify and understand new applications of Geopolitics.
\end{abstract}

Key words: geopolitics, territory, space, strategy, empire, ideology.

\title{
Sumario
}

Las teorías geopolíticas y la extensión territorial

Clasificación de la geopolítica

Relaciones de la geopolítica con otras ciencias

Racionalismo, determinismo y organicismo como

fundamento filosófico de la geopolítica 


\section{INTRODUCCIÓN}

El las páginas siguientes, se exponen los principales elementos teóricos de la geopolítica, como contribución al renacimiento de esta ciencia que retoma su dinámica con la globalización. La importancia del tema radica en que su práctica, al inicio del siglo XX, favoreció la extensión territorial de algunos estados y hoy se presenta como forjadora de verdaderos imperios económicos ${ }^{2}$.

"Geopolítica es el estudio de la influencia del espacio geográfico sobre los estados y su política". Con frecuencia se identifica con la geografía política, de más amplio contenido ${ }^{3}$.

La geopolítica nace de las ciencias políticas y de la geografía política, y por lo tanto, hace parte de las primeras y se constituye en una ciencia dinámica que estudia la influencia de los factores históricos, políticos, sociales y económicos en la vida y proyección del Estado y por lo tanto, sus conclusiones son de tipo político; es útil para deducir necesidades y determinar los objetivos del Estado con miras a mantenerlo o como forma de alcanzarlos, para lo cual, se basa en la geografía política. A la inversa, establece las consecuencias geográficas de una política y guía al estadista y al conductor político. Otra definición difundida por el Instituto de Geopolítica de Alemania, argumenta que "Geopolítica es la doctrina de las relaciones terrestres, de los desarrollos políticos" y se basa en los amplios fundamentos de la geografía, especialmente de la geografía política, y es la doctrina de los organismos espaciales políticos y de su estructura. Esta definición, sin embargo, no coincide con la que propuso RUDOLF KJELLÉn, para quien la geopolítica es "la doctrina del Estado considerado como un organismo geográfico o fenómeno del espacio ${ }^{4}$ ".

2 González Posse, Ernesto, La frontera como factor de integración. Intal. Buenos Aires, Argentina, 1990, pág. 266.

3 López Trigal, Lorenzo y Del Pozo, Paz Benito, Geografía política. Edic. Cátedra S.A. Madrid, 1999, pág. 283.

$4 \quad$ Dorpalen, Andreas, The world of general haushofer. New York, 1942, pág. 23. 
La geografía política es la ciencia madre de la geopolítica y hace parte de la ciencia geográfica; es una ciencia estática que estudia la tierra como hábitat del hombre en un momento dado y sus conclusiones son eminentemente geográficas. Es útil para conocer condiciones específicas de un problema y se basa en la geografía humana; considera al mundo dividido en estados para estudiar la organización político administrativa de cada uno de ellos. La geopolítica sirve de fundamento y propone directrices de acción a la política, subordinándose a ella y poniendo a su servicio, acontecimientos de la ciencia geográfica ${ }^{5}$. Tres formas distintas dieron origen al renacimiento de la geopolítica:

1. El término geopolítica se empezó a utilizar para referirse a la rivalidad global en la política mundial y su etimología ha sido aprovechada para referirse a un proceso general de organización, con el objeto de lograr un equilibrio de poder.

2. La preocupación de la academia ha propendido por la aparición de una geopolítica moderna y es así como los historiadores críticos han pasado a formar parte de esta geopolítica de los geógrafos, investigando entre otros temas, la geografía de la guerra y de la paz. Sin embargo, y pese a muchos esfuerzos, la geopolítica todavía se presenta como rival de la geografía política.

3. La guerra fría involucró grupos de presión pro militares y neo conservadores que utilizando argumentos de la geopolítica, la aprovecharon en su favor, para tratar de balancear los espacios de poder, con el pretexto de imperativos geopolíticos, al considerar que la geografía ha sido el factor permanente alrededor del cual, debe girar todo el pensamiento estratégico.

En el estudio de las relaciones internacionales, existen dos tradiciones intelectuales acerca de las relaciones internacionales, estrechamente ligadas con la geopolítica, y que se han denominado realismo e idealismo. La primera predominó y se fue conformando a partir de una serie de obras clásicas sobre el arte de gobernar y la rivalidad interestatal, entre las cuales vale la pena destacar la de MAQUIAVELO y la de Clausewitz. Estas teorías enfatizan en que el Estado permanentemente se encuentra en situación de inseguridad y por consiguiente, recomiendan adoptar diversas medidas que se inscriben en una política de poder que en el fondo, significa que los estados más fuertes imponen su voluntad a los más débiles. Es por esto, que la guerra o la amenaza de invasión tiene un papel trascendental en esas recomendaciones realistas de las relaciones internacionales. Los idealistas por su parte, rechazaron esas recomendaciones y tildaron a los realistas como amorales, pues ellos

García Negrete, Jorge, Esquema para una investigación geopolítica, en Revista Geográfica, no 4, Instituto Militar Geográfico. 1982. Quito, Ecuador, 1989, págs. 27-58. 
practicaban una doctrina liberal que intentaba asegurar las relaciones internacionales sobre bases constitucionales firmes y no sobre el realismo conservador que ha favorecido y favorece a los más fuertes.

Por tradición, la geopolítica estuvo inmersa en el determinismo de los realistas y esa fue una de las causas para no desarrollarse y para ser excluida del mundo académico. Las teorías del poder relacionaron los espacios físicos con la dominación del mundo, y aunque en la actualidad, algunos países desarrollados las aplican con éxito, la teoría liberal de los idealistas intenta la aparición de un nuevo mundo, donde los estados conserven su autonomía lejos del colonialismo y la dependencia.

Cuando se habla de geopolítica, por necesidad, debe referirse a la teoría del corazón continental (Heartland), de sir HALFORD MACKINDER, pues en el transcurso de todos los tiempos, se ha considerado el modelo geográfico más conocido en el mundo y en la actualidad, las discusiones sobre política exterior se inspiran en ella, en especial, en cuanto a la doctrina militar occidental. Por primera vez en 1904, esta teoría se presentó en una conferencia con el nombre de El pivote geográfico de la historia y luego, en una segunda presentación después de la Primera Guerra Mundial, se retocó con el nombre de Ideales democráticos y realidad ${ }^{6}$.

Aunque muchos estrategas se inspiraron en MACKINDER, en la actualidad, muchos lo consideran más un economista político que un geoestratega de quien siempre se habló en geografía política ${ }^{7}$. Es posible que MACKINDER hiciera una aplicación práctica de la geografía al referirse a las enseñanzas del maestro Sun Tzu, que desde el año 475 a.C., en su libro clásico El arte de la guerra, escribió sobre la importancia del terreno, el territorio, el espacio, el Estado y el poder:

Según las reglas de las operaciones militares hay nueve clases de terrenos. Donde los intereses locales pelean unos contra otros, es lo que se llama terreno de disolución. Cuando penetras en territorio ajeno sin profundidad, se llama terreno liviano. El espacio que puede ser ventajoso para cualquiera de los contrincantes se llama terreno de contención. La tierra en la cual ambos bandos pueden ir y venir, se llama terreno transitado. La tierra que tiene tres lados rodeados por el enemigo y uno de unión con el terreno propio, se llama terreno de intersección. Cuando se penetra profundamente en el territorio enemigo, cruzando muchas ciudades y pueblos se llama terreno pesado. Cuando se cruzan montañas selváticas, desfiladeros empinados, ciénagas, o cualquier campo difícil de transitar, se llama terreno malo. Cuando el camino es estrecho y la salida tortuosa, de manera que una pequeña fuerza enemiga pueda atacar, aún cuando se tenga un número mayor, se llama terreno rodeado. Cuando se puede sobrevivir si se

Ibáñez SÁnChez, José Roberto, Teoría del Estado. Geopolítica y geoestrategia. Colección de Oro del Militar Colombiano, vol. XVII. Imprenta y Publicaciones de las Fuerzas Militares. Santa Fe de Bogotá, 1985, pág. 77.

7 TAYLOR, PETER J., Geografía política - Economía-mundo, Estado-nación y localidad. Trama Editorial. Primera edición en español. Madrid, España, 1993, pág. 51. 
batalla con rapidez o al contrario, perecer, se llama terreno de muerte. Así, pues, no debes batallar en un terreno de disolución, no debes detenerte en un terreno liviano, ni atacar en terreno de contención, ni dejarte aislar en un terreno transitado. En terreno de intersección debes crear comunicaciones; en terreno pesado saquea, en terreno malo sigue; en terreno rodeado haz planes, y en terreno de muerte, ipelea! ${ }^{8}$.

Esta cita permite entender cómo la geografía ha sido un factor importante en la guerra, desde que el hombre existe. De igual manera, explica el interés especial de los militares del mundo por incluir en sus programas académicos, nociones y especialidades de geografía. A escala mayor, también explica la práctica de la geopolítica como medida eficaz para mantener el orden mundial que en un principio, se constituyó en bandera de realistas y conservadores, y que en la época moderna, ha sido combatido por los idealistas liberales. Este orden es respetado por unos y despreciado por otros, pero al fin y al cabo, es orden ${ }^{9}$.

Pese a que en la mayoría de estudios sobre las relaciones internacionales del período de entre guerras, predominaba el pensamiento de los idealistas, en un rincón de Europa, en la derrotada Alemania, triunfaron las tesis realistas acerca de la situación mundial, porque en ese país, el idealismo estaba desacreditado porque se relacionaba con el Tratado de Versalles ${ }^{10}$ y Postdam (1919-1945), y con el cual, cayó el Hito de la Guerra del Vietnam. El objetivo de la geopolítica alemana fue entonces, la revisión del Tratado de Versalles que justificó, mediante el espacio vital, término original de FRIEDRICH RATZEL, con el cual, había argumentado que los problemas de Alemania se debían a que el país tenía unas fronteras injustas que la aprisionaban, y por lo tanto, necesitaba expandirse.

Al comparar la geopolítica alemana de la década del cuarenta del siglo XX, con la doctrina nacional socialista, se puso de manifiesto las diferencias fundamentales entre las dos teorías. Mientras la geopolítica mencionada estaba inspirada en el materialismo científico de RATZEL, el nacional socialismo se apuntalaba sobre la idea de la existencia de cualidades humanas de tipo genético, con lo cual, se exaltaban las teorías de superioridad racial. HAUSHOFER intentó anular las diferencias en-

8 Tzu, Sun, El arte de la guerra de Wu Sun. Tercera edición. Tercer Mundo S.A. Elektra Editores. Santa Fe de Bogotá, 1997, pág. 100.

9 Chomski, Noam, La nueva estrategia militar de Estados Unidos, en Ceopolítica del Caos. Le Monde Diplomatique. Edición española. Editorial Debate, Barcelona. 1999, pág. 28.

10 La Paz de Versalles, a pesar de sus grandes yerros, tuvo el acierto de reconocer la soberanía de las pequeñas naciones europeas. Aunque éstas quedaron en una situación de indiscutible inferioridad porque se organizaron en pequeños estados y porque, dado el carácter agrario de su economía, debían caer bajo la dependencia económica de las grandes potencias industriales, no puede, sin embargo, dejarse de considerar como un gran paso en el camino de la reorganización política del mundo la formación de los estados nacionales europeos. 
tre las dos teorías, facilitando las relaciones entre el Tercer Reich y el mundo académico, y por esta razón, la geografía se convirtió en la disciplina científica a la que se culpó con mayor fuerza, de la legitimación del régimen nazi. Hoy se le culpa de otros problemas, conforme con la siguiente cita:

La geopolítica contemporánea se caracteriza por una compleja coexistencia de espacios absolutamente controlados y de territorios planificados, al lado de nuevas tierras incógnitas que funcionan con una lógica interna propia, al margen del sistema que los ha engendrado. La guerrilla zapatista, los narcotraficantes colombianos, los señores de la guerra somalíes, las tribus urbanas o las mafias rusas se nos aparecen como nuevos agentes sociales creadores de nuevas regiones, con unos límites imprecisos y cambiantes, difíciles de percibir y aún más de cartografiar, pero enormemente atractivas desde un punto de vista intelectual ${ }^{11}$.

\section{LAS TEORÍAS GEOPOLÍTICAS Y LA EXTENSIÓN TERRITORIAL}

Las teorías del dominio del corazón de la tierra, del dominio del mar y del dominio del espacio aéreo, hicieron que la geopolítica mostrara en toda su plenitud, una importancia vital, pues por medio de ellas, los diferentes espacios eran los factores preponderantes en las relaciones de poder. Hoy se afirma con razón o sin ella, que la globalización de los negocios que realizan las empresas transnacionales, permite traspasar fronteras, sin que se presenten los delicados problemas de las relaciones internacionales, entre los supuestos agredidos y agresores. Sin embargo, "la frontera política, considerada bajo el ángulo de un límite de soberanía, sigue siendo por esencia, el perímetro espacial y legal del sistema político" ${ }^{12}$. Mencionaré de manera breve, esas teorías geopolíticas:

a. El mar y la teoría de Mahan. El almirante americano Alfred ThAYER MAHAN fue el primero que elaboró un trabajo estructurado al respecto, The influence of sea power upon history escrito en 1890, con el cual, surgió como el primer geopolítico en los cinco continentes. De la estructura del mundo y la acción naval de Gran Bretaña, extrajo los principios que debían servir como guía para un posible dominio del globo. Esta teoría consistía en que la nación que quisiera conquistar el mundo, debía ser rica y esa riqueza la lograría por medio de una gran industria que debía abastecerse de materias primas transportadas por una marina eficiente que a su vez, llevaría los productos manufacturados a los principales centros de comercio y trazaría así, una especie de figura cerrada en movimiento constante. "Dominio terres-

\footnotetext{
11 NOGuÉ, Fon y Rufí, JOAn, Geopolítica, identidad y globalización. Ariel Geografía. Madrid, España, 2001, pág. 8.

12 Sancuin, André-Luis, Geografía política. Elementos de geografía. Oikos-tau, S.A. Barcelona. 1981, pág. 17.
} 
tre es el control político y militar sobre el heartland; pero si se posee también el control de los mares, su dominio puede ser universal ${ }^{13}$ ".

Sin embargo, era lógico que esas líneas de navegación pasarían muy cerca de lugares donde estarían en peligro de ser interceptadas, cuando llegasen a abastecerse de agua, alimentos, combustibles o productos naturales, y para evitar este contratiempo, no era factible otro sistema de defensa que adueñarse de esas bases, por medio de tratados o por la fuerza. Para tal fin, Inglaterra estableció varios ejes de navegación con los cuales, se fueron apoderando de ciertos puertos, islas o estrechos y así, 16 puntos cayeron bajo su dominio: Gibraltar, Malta y Suez sobre el Mediterráneo; Terranova, Jamaica y las islas Fakland o Malvinas en América; Suráfrica y Diego Suárez en África; Yemen, India, Singapore, Darwin, Tasmania, Srawak y Nueva Zelanda en Asia ${ }^{14}$. En la actualidad, algunos países se reúnen con la Gran Bretaña, en busca de que les sean devueltos los territorios les arrebató durante la época de su predominio, y una cruenta guerra libró Argentina en 1982, cuando trató de recuperar las islas Malvinas, con resultados negativos.

b. La tierra y la teoría de Mackinder. El 25 de febrero de 1904, el profesor inglés sir HARLFORD MACKINDER, director del Observatorio Astronómico de Greenwich y profesor de geografía de la Universidad de Londres, pronunció la conferencia $E l$ pivote geográfico de la historia que causó profunda impresión en todo el mundo, por haber sido diseñada como uno de los fundamentos de la geopolítica. MACKINDER sostenía que MAHAN se había equivocado. Las líneas férreas habían avanzado técnicamente y se observaba la tendencia a formar continentes compactos. Según el profesor, la parte enjuta del globo era el medio único para lograr la conquista mundial; en esa mitad seca, se encontraba todo lo grande hecho por el hombre: la cultura, la riqueza, la ciencia, y allí también, se hallaban los elementos dominantes de la humanidad. De igual forma, sostenía que los medios o elementos de comunicaciones de la época, permitían que a los puertos llegaran oportunamente, las fuerzas suficientes para alejar a los barcos que arribaran ${ }^{15}$.

Basado en mapas cuidadosamente preparados, Mackinder demostró que existía una extensa área situada en la parte occidental y continental de Rusia, ceñida al norte por el Ártico, al sur y al sureste por grandes cadenas montañosas de Europa y Asia; y al oeste por la fosa del Volga que se alargaba hasta la profunda entrada del

13 Ceresole, Norberto, Tecnología militar y estrategia nacional - Política y economía de la defensa. Editorial Pleamar. Buenos Aires, 1991, pág. 152.

14 Londoño Paredes, Julio, Los fundamentos de la geopolítica. Colección de Oro del Militar Colombiano, vol. IX. Imprenta y Publicaciones de las Fuerzas Militares. Bogotá, D.E., 1978, pág. 14.

15 Ibíd., pág. 21. 
Mar Báltico. Precisamente a esa zona la llamó Pivote geográfico de la historia, nombre que sus comentadores cambiaron por el de Europa Central. Sostenía también, que esa región no puede ser atacada por mar, como creía MAHAN y para su defensa por tierra, contaba con poderosos ejércitos de infantería. Ese pivote se encontraba rodeado de una serie de penínsulas que formaban una especie de reborde protector que MACKINDER llamó La región marginal creciente, que a su vez, estaba protegida por una serie de islas, algunas continentales y otras lejanas, a esa faja casi circular que envolvía desde lejos el pivote, la denominó La tierra de la región insular creciente.

En sus mapas, MACKINDER hizo notar el error común de hablar de tres continentes al mencionar a Europa, Asia y África, puesto que los tres están física y estrechamente unidos por la extensa región del Medio Oriente. En su opinión, ese espacio no forma tres continentes, sino una gigantesca isla que llamó La isla mundial. En ella, cualquier potencia podría encontrar todos los medios necesarios para conquistar el mundo: hombres, materias primas, la más apta y numerosa juventud, así como la industria y el dinero que necesitara. Una vez estudiadas y evaluadas estas tres áreas, MACKINDER formuló la ley que lleva su nombre y que los críticos elogian o combaten de continuo: 1. "El que domine la Europa Central, controlará el corazón mundial. 2. El que controle el corazón mundial, dominará la isla mundial. 3. El que domine la isla mundial, dominará el mundo ${ }^{16}$ ".

Destacados analistas revisaron la teoría de MACKINDER, entre ellos Nicolás SPYкMAn, profesor emérito de la Universidad de Yale que sostuvo sus puntos de vista en su libro Geografía de la paz, escrito en 1944 y que hoy sigue siendo base de consulta para quien se interese en la geopolítica mundial.

Spykman sostuvo que esta política mundial por firme que parezca, cambia con suma facilidad y que MACKINDER había dado a su ley, un carácter permanente, inadecuado para los tiempos modernos y además, concebía la geopolítica en una forma diferente. La geopolítica - decía— - "es el planeamiento de la seguridad política de un país en términos geográficos". Los dos términos fundamentales, para SPYKMAN son espacio y tiempo. Por espacio, entendió la localización del Estado que varía con el crecimiento o decrecimiento de los centros mundiales de poder o con el crecimiento o decrecimiento de las grandes potencias que tengan relación con el Estado. Por tiempo geopolítico, entendió el poder del Estado en comparación con los demás.

El rimland (borde-cerco-orilla), como SPYKMAN llamó al exterior creciente, es una zona de inmenso valor, por ser invulnerable a la marina, pese a la teoría de

16 Ibíd., pág 19. 
Mahan. En esta forma, SPYKman estableció una nueva ley: "Quien domine el rimland, dominará a Eurasia. Quien domine a Eurasia, dominará el mundo ${ }^{17}$ ". Complementó su principio con la idea de que la cooperación entre marina y aviación son indispensables para obtener el éxito. Se empezó a hablar entonces, de las operaciones conjuntas en el campo militar, lo cual permitió el desarrollo acelerado de estas dos especialidades.

c. El aire y la teoría de Reigner: El gran investigador ROBERT HUTCHINGS GODDAR, advirtió que las especulaciones relacionadas con el dominio del globo por medio del aire, jugaban un papel de importancia suma, en esos momentos, cuando el hombre iniciaba el dominio del espacio (atmosférico) ${ }^{18}$, campo en donde se alcanzó en diez años, un adelanto no soñado en diez siglos, y avanzó con tal rapidez que dejó atrás a todos los progresos logrados a partir de las ideas de MAHAN y de MACKINDER. A tal punto llegó esta diferencia, que a nadie extrañó que Hutchings afirmara que

la física y la química han llegado a producir medios de destrucción ante los cuales las bombas atómicas lanzadas sobre las ciudades japonesas de Iroshima y Nagasaki, son juguetes comparados con las actuales dada su inmensa capacidad destructiva, sin tomar en cuenta los medios secretos que ocultan celosamente los adversarios para un caso decisivo.

sin olvidar un hecho que empeoraba la situación, cual es la explosión demográfica que aumenta las posibilidades de muerte en forma incalculable. Hutchings acertó, porque hoy, el fenómeno de la guerra no se desarrolla a campo abierto, sino que tiene a la ciudad como su gran objetivo.

La tendencia irrefrenable de la gente a agruparse en las grandes ciudades, permite a los medios actuales destruir una urbe millonaria en pocos segundos. Además, el acelerado crecimiento de las ciudades, llegará a convertir a Europa en una sola urbe, transformando a las metrópolis que han sido llamadas el protofenómeno de la sociología, porque después de la II Guerra Mundial, los medios que utilizaban para su defensa, ya no tengan vigencia. En la metrópoli actual, todos los medios y servicios son interdependientes; la falla de uno cualquiera, acarrea la paralización de casi todos los demás: electricidad, gas, agua, transporte, salud, comunicaciones y muchos otros.

Estas consideraciones sumadas a los progresivos adelantos de la técnica destructora, han llevado a la clara concepción política de que una verdadera conquista mundial debe dejar la tierra y el agua, y basarse en los postulados reales del mo-

\footnotetext{
Ibíd., pág 21.

18 El geógrafo alemán Friedrich Ratzel aseguraba que la decadencia de todos los estados es el resultado de una decadente conciencia de espacio en sus respectivos pueblos.
} 
mento. El profesor francés De REIGNER, acompañado por un amplio grupo de técnicos, planteó la situación de la siguiente forma: el gran blanco estratégico actual es la gran ciudad y de su destrucción depende la victoria ${ }^{19}$. El mundo — dijo— con la desordenada distribución humana en la corteza terrestre, ha hecho que los tres continentes, Europa, Asia y América, reúnan sus grandes masas terrestres en el polo norte. De 140 ciudades de más de un millón de habitantes, más o menos 120 están al norte del trópico de cáncer. El resto se dispersa en fajas verticales separadas hacia el sur, sin mayor comunicación entre ellas. Por esta razón, el casquete norte mundial es la base de la actual civilización, y la región que va adelante y dirige la historia del mundo. Por otra parte, las vías aéreas hacia ella, son más cortas y aptas para la sorpresa y las que ofrecen mayores dificultades para la defensa. En un universo polarizado como el actual, la destrucción de las ciudades principales llevaría, si es posible la respuesta del contrario, a la total destrucción de la civilización, y siguiendo la tentación de las naciones a destruirse, se confirmaría lo expresado por RATZEL, que en la Tierra, sólo hay lugar para una gran potencia.

El ataque del 11 de septiembre de 2001 a las Torres Gemelas de Nueva York, dio la razón a REIGNER y a RATZEL, pues una operación corta, sencilla y de bajo costo en términos económicos, comparada con los medios convencionales, causó miles de muertos y despertó la furia del gobierno de los Estados Unidos que inició una campaña militar de gran escala, fundamentada en la guerra preventiva contra el terroris$\mathrm{mo}^{20}$. Así entonces, las tres teorías esbozadas someramente, implican el apoderamiento de un espacio, bien sea sobre la superficie terrestre, el mar o el espacio aéreo, con el objetivo específico de dominio total, porque el poder siempre se ha fundamentado en el espacio ${ }^{21}$.

\section{CLASIFICACIÓN DE LA GEOPOLIITICA}

El objeto de estudio de la geopolítica lo constituyen las relaciones entre los factores geográficos, sociológicos, económicos y políticos con las instituciones políticas y

19 Gorce de la, Paul-Marie, El papel de la onu, ocupado por la otan. Organizaciones internacionales, alianzas y caos geopolítico: ¿debatir el papel de la onu?, en Geopolítica del caos. Le Monde Diplomatique. Edición española. Prólogo de Manuel Vázquez Montalbán. Temas de debate. Primera edición. Madrid, 1999, pág. 35.

20 Cuando el diccionario de la Real Academia Española define el término que el presidente George W. Bush puso a circular desde el 11de septiembre de 2001 ("guerra preventiva"), nos dice que es "la que emprende una nación contra otra presuponiendo que ésta se prepara a atacarla". De su boca ha salido sin fatiga el término "amenaza terrorista".

21 Castles, M. y Kovack, G., Revolución tecnológica y reestructuración económico-política del sistema mundial. Impactos de la tecnología avanzada sobre el concepto de seguridad. Editorial Frepi. Madrid, 1978, pág. 86. 
la vida del Estado. De la forma general o particular como se realice el estudio, dependerá la clasificación de la geopolítica. Si dichas relaciones se ejecutan con criterio amplio e indeterminado, sus conclusiones serán de aplicación universal, sin que por ello signifique un carácter absoluto, sino general. En este caso, estamos frente a la geopolítica general. "La geopolítica se origina en el concepto de que la naturaleza en tanto tal, con sus efectos sobre el hombre, regula la conducta humana y así, define sus intereses, tal como aseveran los diversos geopolíticos ${ }^{22}$ ". Pero si se estudia la geopolítica de un Estado o la influencia de un determinado factor geográfico, sociológico, económico, político u otro, en la vida de uno o varios estados, nos encontramos con la geopolítica particular. Por este motivo, existen obras de geopolítica nacional que obviamente se refieren a un país específico o de geopolítica del hambre, de la pobreza o de las enfermedades, para señalar la influencia de estos flagelos en ciertos estados o regiones que los padecen.

Como resultado de las diversas corrientes de la geopolítica, con frecuencia se la clasifica o califica en forma inapropiada. Por ejemplo, cuando se dice que un Estado expansionista tiene conciencia geopolítica, se interpreta la geopolítica con criterio determinístico, como si el factor espacial fuera el todo de su contenido. Otras clasificaciones de la geopolítica corresponden a su interpretación conforme con la escuela de que se trate:

Entre las más sobresalientes, encontramos la escuela alemana orientada por FRIEDRICH RATZEL, KARL HAUSHOFER y RUdOLF KJELLEN ${ }^{23}$, que se considera organicista y determinística por el espacio y la particular situación de las ambiciones alemanas en el pasado; a partir de 1945, hablar de geopolítica era inscribirse en el nacional socialismo de la Alemania del Führer. Sin embargo, las grandes potencias hacían seguimientos a las investigaciones de los institutos de Geopolítica de Munich y Heidelberg. Esto confirma la importancia del tema y el temor que despertaba la geopolítica, como elemento clave para mantener el poder relativo de combate de los estados interesados, es decir, la geografía no dejó de ser un terrible instrumento de poder. Es importante resaltar que Alemania ha sido la cuna de todas las disciplinas geográficas, y sus primeros sistematizadores fueron ALEXANDER Von HuMBOLDT y KARL RITTE ${ }^{24}$.

22 Small, Gretchen y Small, Dennos. El complot para aniquilar a las fuerzas armadas y a las naciones de Iberoamérica. EIR-Resumen Ejecutivo. ISBN: 0-943-235-15-4. Washington D.C., 1997, pág. XI.

23 El geógrafo sueco Rudolf Kjellén había acuñado un nuevo nombre para los estudios de geografía política aplicada, el de geopolítica y sus ensayos contribuyeron a darle a ésta un impulso imprevisto sobre todo en Alemania. Pero el abanderado de estos trabajos desde el primer momento, fue Karl Haushofer, organizador del Institute für Geopolitik de Munich, fundado en 1925, director del Zeitschrif für Geopolitik, y animador de las diversas ramas de la geografía aplicada surgidas en corto tiempo.

24 Vivó, JorGe A., “Jornadas”. La geopolítica. El Colegio de México. Centro de Estudios Sociales. 1943, pág. 14. 
La escuela inglesa de MACKINDER, fundada en el dominio del mundo, por la repartición del mar y de la tierra, bajo el presupuesto de que la nación que tenga este doble poder y se sustente en una masa terrestre considerable y orientada por el Heartland, será la dueña del universo. MACKINDER fue quien realizó los esquemas geopolíticos trascendentales y audaces que inspiraron a toda la escuela alemana ${ }^{25}$.

La escuela norteamericana representada por el almirante MAHAN, DORPALAN, WeIGER y SPIKMAn principalmente, se enfocó a desvirtuar la geopolítica alemana y a mantener la vigencia de la geografía política, confundiéndola con la geopolítica, aunque creó métodos didácticos y analíticos. Al principio de la década de 1940, STRAUSz predijo que el papel predominante que asumiría Estados Unidos en la economía mundial, sería de tal fuerza que no requeriría expansión territorial alguna. Fue el mismo STRAusz quien expuso las proyecciones de la geopolítica de su país: "aunque los Estados Unidos no tienen interés en obtener porciones de los espacios que logren como resultado de su esfuerzo militar, sí tienen el interés inmediato de implantar y mantener un orden universal que será la compensación de sus sacrifi$\operatorname{cios}^{26}$ ". La seguridad de este orden universal dependería en última instancia, de la fuerza armada, lo mismo que la seguridad de cualquier sistema político, aunque la fuerza armada necesaria sea muy pequeña.

La escuela francesa de VIDAL DE LA BLACHE, analizó la influencia de los fenómenos geográficos en la vida del Estado, y otros más, basados en la actividad humana, en la capacidad del hombre para modificar la geografía y aún, el ambiente. En general, destaca la importancia de las relaciones, los intercambios y las comunicaciones en la vida nacional, importancia que ha ido creciendo en la medida de las conquistas técnico científicas ${ }^{27}$.

La escuela soviética, un tanto desconocida en lo teórico, en la práctica guarda la heredad expansionista de los zares y retoma la escuela alemana, para implantarla en la ideología y praxis socialistas, moldearla con la dialéctica y enriquecerla con las conquistas logradas a partir de la II Guerra Mundial. El autor ruso M. ILLÁn presentó con mano maestra, un cuadro con las aplicaciones que de las ciencias geográficas se ha hecho para conquistar y adaptar el medio de extensas regiones de la Unión Soviética.

25 MaCkInder, Halford, The geographical pívot of history. Londres. The Royal Goegraphical Society. 1944, pág. 128.

26 Strausz-Hupe. Geopolítica. Nueva York, 1942, pág. 176.

27 Derek, Gregory; Ron, Martín y Smith, Graham. Human. Geography. Society, Space, and Social Science. University of Minnesota Press. 1994, pág. 96. 
La escuela italiana, con su reivindicación colonial e imperial, centrada en un espacio vital mediterráneo que soñaba la autarquía con las reclamaciones sobre Istria y la costa dálmata, además de Albania, Grecia e importantes áreas del norte de África. Exaltaba el imperio romano y el nacionalismo, en contraposición a los avances de las tesis internacionalistas, socialistas y comunistas en Italia. Su discurso geopolítico facilitó la llegada del fascismo al poder y adoptó características similares a las de la Geopolitik alemana ${ }^{28}$.

Aunque no propiamente como escuela, la geopolítica española ha tenido altibajos; primero, por su cercanía con la escuela alemana, en especial, con el significado del lebensraum que en consonancia con la tradición española, permitía justificar la necesidad de consolidar las colonias norteafricanas. Como en la mayoría de los países, la geopolítica española languideció y se mantuvo tan sólo en los círculos militares. En la época actual, la geopolítica ha reaparecido desde los medios de comunicación y el periodismo, en forma de opinión o como mera información, aunque desde las relaciones internacionales y la estructura administrativa del Estado español, con una dinámica propia ${ }^{29}$.

Por último, la escuela brasilera que nació a partir de la creación de la Facultad de Filosofía, Ciencias y Letras de la Universidad de São Paulo y la fundación de Geógrafos brasileños en 1934. Inspirada en la orientación metodológica francesa, se ha dedicado al estudio e investigación de temas ligados directamente con la geografía brasilera, en especial con la geografía humana. Su preocupación actual es formar geógrafos tropicales, debido a que las dos terceras partes del mundo ocupan zonas tropicales. Su más importante exponente fue MiLton SAntos que planteó la renovación de la geografía. De todas maneras, la importancia que logró la geopolítica a comienzos del siglo XX, produjo expresiones como la siguiente, que demuestra la aversión que llegó a generar en ciertos círculos:

La geopolítica, claro, es de particular importancia, ya que es el dogma reinante, más o menos desde la década de 1880 en esa forma, de la fuerza oligárquica culpable de las dos guerras mundiales que ha habido en el siglo XX, y de las diversas formas colonialistas y neocolonialistas de fines del siglo XIX, y del siglo XX, incluida la forma neocolonialista que los británicos y otros paganos del mismo parecer (como Felipe o Carlos, de la familia real británica, quienes han promovido el culto a Gaia) pretenden imponerle al mundo ${ }^{30}$.

La cita precedente es fiel reflejo de aquella culpa que todavía se le asigna a la geopolítica, al asociarla como herramienta del poder que despertó intereses

\footnotetext{
28 Nogué, Foni y Rufí, Joan. op. cit., pág. 52.

29 Ibíd., págs. 59-60.

30 SMALL, op. cit. pág. XII.
} 
expansionistas y llevó a la guerra, a diferentes Estados que tardaron varias décadas en recuperarse.

\section{RELACIONES DE LA GEOPOLIITICA CON OTRAS CIENCIAS}

En la actualidad, la geopolítica ha recobrado especial importancia, debido a que la globalización económica trasciende las fronteras nacionales e internacionales, mediante los intercambios comerciales, lo cual no obsta para que se revisen los procesos geopolíticos. En tal virtud, es conveniente mostrar cómo la geopolítica, para cumplir con su objetivo, se relaciona con otras ciencias:

Con la geografía: ya se anotó cómo la geopolítica tuvo como ciencias madres, a la ciencia política y a la geografía, debido a que quien pretende estudiar geopolítica, debe poseer conocimientos geográficos, especialmente en la rama de la geografía política. De lo contrario, sería como pretender multiplicar sin saber sumar; sin embargo, esto no significa que la política y la geografía sean los únicos fundamentos de la geopolítica, puesto que a ellas concurren diversas ciencias.

Con la sociología: si la geopolítica estudia las relaciones hombre-suelo o mejor, humanidad-territorio, automáticamente queda de manifiesto la comprensión del medio social que habita y explota ese territorio. De esta forma, la geopolítica se interrelaciona con la sociología, para analizar las características de la sociedad que conforma el Estado. No hay que olvidar que lo que conocemos como identidad proyecto, se materializa cuando los actores sociales construyen una nueva identidad, sobre bases culturales que redefinen su posición en la sociedad y buscan la transformación de toda la estructura social ${ }^{31}$.

Con las ciencias económicas: la geopolítica se relaciona profundamente con la economía, por ser ésta, el fundamento del desarrollo de los Estados. Los recursos naturales del territorio, en especial los que más influyen en los factores del poder, son de particular interés y análisis por parte de la economía, para proyectar la vida del Estado. "El crecimiento de la Unión Europea y la configuración de una Zona Norteamericana de Libre Comercio, por ejemplo, son en parte, intenciones de ejercer influencia política sobre los asuntos económicos a una escala mayor que la del Estado nacional ${ }^{32} "$.

31 Unwin, TIM, El lugar de la geografía. Editorial Cátedra. Traducción de Jerónima García Bonafé. Madrid, España, 1995, pág. 222.

32 PAINTER, JOE, Lecturas en geografía, en Política, geografía y geografía política. Facultad de Ciencias Humanas. Departamento de Geografía. Artículo traducido por Ovidio Delgado Mahecha. Santa Fe de Bogotá. 1998, pág. 124. 
Con la historia: la historia es el puntal de muchas ciencias, entre ellas, la geopolítica que fundamenta buena parte de sus estudios, en experiencias del pasado. La filosofía de la historia nos lleva a comprender la existencia de una serie de sucesos humanos que se repiten en ciclos de tiempo, sin ser fruto del azar, sino de principios sociales y naturales, a los cuales se dedica con profundidad de análisis, la geopolítica. Las relaciones de la geopolítica con la historia son de tal magnitud que algunos autores pretendieron cambiar su nombre por el de geohistoria ${ }^{33}$.

Con la filosofía: el discurso humanístico de la filosofía en búsqueda de la verdad, implica mejorar las condiciones de vida del objeto de su interés, el hombre, y por lo tanto, el determinismo ha sido suavizado por la teoría social que trata de explicar el comportamiento humano, desde ángulos diferentes al entorno físico ${ }^{34}$.

Con las ciencias militares: las conclusiones de la geopolítica buscan encauzar la conducción del Estado al mantenimiento y/o logro de sus objetivos políticos. Estos objetivos tienen por lo tanto, la particularidad de lograrse por medios pacíficos o por la fuerza, aisladamente o en alianza con otros Estados, y es entonces, cuando entra en juego la estrategia militar para analizar la viabilidad de alcanzarlos a la luz de los medios humanos y materiales de que dispone el Estado o el bloque de Estados, además de las consideraciones geográficas imperantes. En esta forma, la estrategia militar aparece como ciencia hermana o paralela de la geopolítica, la geoestrategia o estrategia tridimensional de grandes espacios, que estudia los factores físicos que influyen en la estrategia, considerada ésta en su más alto nivel ${ }^{35}$.

La estrategia es la rama de las ciencias militares, cuyo fin es la conducción general de la guerra y la organización defensiva de una nación. La geoestrategia, entonces, es la parte de la geografía política que analiza la organización en el espacio, de las fuerzas militares, políticas y económicas implicadas en una guerra o en las operaciones de defensa de un territorio ${ }^{36}$.

33 LACOSTE, YVES, La geografía: un arma para la guerra. Elementos críticos. Edit. Anagrama. Barcelona. 1977, pág. 9.

34 VÁsquez SÁnCheZ, JAIME, Estrategias geopolíticas y posibilidades para un nuevo ordenamiento territorial en el medio rural, en Memorias XVI Congreso Colombiano de Geografía. Santiago de Cali. 2000, pág. 54 .

35 LuCBert, MAnuel, Geopolítica de Asia Central: India como centro. Capítulo 8 Introducción, en Geopolítica del caos. Le Monde Diplomatique. Edición española. Prólogo de Manuel Vázquez Montalbán. Temas de debate. Primera edición. Madrid, 1999, pág, 187.

36 López Trical, op. cit., pág. 282. 


\section{RACIONALISMO, DETERMINISMO Y ORGANICISMO COMO FUNDAMENTO FILOSÓFICO DE LA GEOPOLÍTICA}

En la medida en que el hombre llevó al campo de la utilidad y de la práctica los conocimientos adquiridos, se desarrollaron paralelamente las ciencias y las artes. Hecho que ocurrió con mayor énfasis, en Alemania y tal vez por ello, correspondió a Immanuel Kant intuir la geopolítica, cuando en su obra Sentencias, habló por primera vez de la política geográfica. Es una lástima que este acopio de conocimientos hubiera servido al imperialismo del Kaiser y al nazismo de HitLer, para lanzarse a la conquista de Europa ${ }^{37}$, mitificando su contenido científico con irrealidades tales, como la superioridad $\operatorname{aria}^{38}$. Esto no significa que la geopolítica sea exclusivamente alemana, sino que es una ciencia y como tal, es universal y no sólo tiende a proyectar estados como grandes potencias, sino ayudar también a otros, para mantener lo que tengan e inclusive, enseñar a los Estados pequeños, fórmulas para evitar su desintegración. De igual forma, el filósofo alemán JUAN HERDER en su célebre obra Ideas sobre la filosofía de la historia de la humanidad, afirmó que la nación es un ser orgánico, una planta de la naturaleza. Sus conceptos estuvieron marcados por un determinismo histórico que lo llevaron a hablar del animal nacional y de la fisiología de la nación ${ }^{39}$.

Por esa misma época, el militar alemán Dietrich HeinRich Von Bulow, fundamentó la política exterior sobre condiciones geográficas y separó la estrategia política de la estrategia militar, con un criterio revolucionario e irrespetuoso sobre los valores de la época, que le costó persecuciones y una muerte desgraciada. Sería injusto, continuar cronológicamente con los antecedentes de la geopolítica, sin referirnos a NAPOLEÓN BONAPARTE que resumió su sabiduría político militar en la famosa frase: "la política de los Estados reside en su geografía". De Europa pasamos a América, puesto que la revolución de independencia, de las colonias inglesas del norte y de las españolas del centro y del sur, produjo destacados políticos y militares, uno de los cuales, en la fecundidad de su pensamiento y dinámica de acción, intuyó la geopolítica o al menos manejó los asuntos político militares con criterio geopolítico.

\footnotetext{
$37 \quad$ Un grupo de jurisconsultos germanos realizaron investigaciones de geojurisprudencia y constituyeron la legión de los técnicos y funcionarios del Reich que trabajaban en las diversas disciplinas de la geociencia y de la geotécnica, como se llamó a estas dos ramas matrices en las que entroncaron las ciencias geográficas aplicadas.

38 Strausz, op. cit., págs. 85 y sigs.

39 Worsley, Meter, El tercer mundo. Una nueva fuerza vital en los asuntos internacionales. Traducción de Martí Soler. Siglo Veintiuno Editores. México D.F., 1973, pág, 221.
} 
En Latinoamérica, El Libertador Simón BoLívAR, autor de la Carta de Jamaica, escrita a un caballero inglés, plasmó la más clara expresión de su sentido político geográfico, su profundo conocimiento del medio físico, económico y social americano, y de su genial intuición sobre el destino de cada Estado que nacería de su espada libertadora. En el vasto campo de sus ideas políticas, encontramos destacados visos geopolíticos en la mente de Bolívar. Para defender a Hispanoamérica, de las pretensiones de la Santa Alianza Europea que pretendía recuperar las colonias para España, y con el fin de proyectar mediante una confederación de naciones, la grandeza iberoamericana, promovió en 1826 el Congreso Anfictiónico de Panamá. Pero como este proyecto fracasó por el egoísmo de algunos Estados, insistió en las Confederaciones de los Andes y del Caribe, y hasta su último aliento, propugnó por mantener la unidad de la Gran Colombia. Bolívar luchó hasta su muerte, por demostrar que "toda civilización es en esencia y literalmente, civilización espacial ${ }^{40}$. De esta forma, BolíVAR intuyó cómo los grandes espacios son factores generadores de poder nacional; sus generales no comprendieron lamentablemente, el fenómeno y por el contrario, creyeron que sus servicios a la libertad, les daba derechos feudales y cada uno intentó formar en su región, una república de su propiedad.

El presidente norteamericano JАCOBo MonRoE, coetáneo con el pensamiento bolivariano, forjó la Doctrina que lleva su nombre, con el famoso eslogan América para los americanos, pero quizá sus propósitos llevaban en forma velada, buena dosis de imperialismo a largo plazo. Así lo intuyó BoLívar, en la carta a su amigo inglés: "si nosotros los hispanoamericanos no nos unimos, seremos devorados por el espíritu mercantilista de los ingleses del norte ${ }^{41}$ ".

Para encontrar el camino que nos lleve a comprender mejor la geopolítica, conviene una referencia al filósofo JuAn Fitche, discípulo de Kant y gestor del nacionalismo romántico alemán. En su orden, Guillermo Federico Hegel, gestor del idealismo y la dialéctica, afirmó cómo el sujeto de la historia es el pueblo organizado en un Estado y cómo el nivel humano sólo puede lograrse, dentro del sistema estatal. Afirmó además, con claro acento determinístico, que la historia tiene base geográfica, puesto que el suelo determina el carácter del pueblo que lo habita. Se-

$40 \quad$ CrResole, op. cit., pág. 155.

41 Algunos países europeos, a pesar de que ya había transcurrido más de un siglo que su soberanía en América quedó confinada a las Pequeñas Antillas, las Guayanas, Belice y otras pequeñas posesiones, aún intentaban restablecer su dominio en América. En tal virtud, en 1823 los Estados Unidos proclamaron la Doctrina Monroe, la cual los partidarios de Haushofer consideraron como el primer esquema geopolítico lanzado al mundo para defender su independencia y la de los estados latinoamericanos frente a agresiones europeas y que más tarde emplearon sistemáticamente para justificar las agresiones dirigidas contra algunas naciones del sur. 
guidor de MAQUiavelo en lo moral, sostuvo que los principios éticos deben sacrificarse en beneficio del Estado ${ }^{42}$.

Alejandro de Humboldt ocupa también, un lugar preeminente como precursor de la geopolítica. En efecto, en su obra Ensayo político sobre el reino de nueva España, analizó los hechos geográficos y su relación con la vida humana, y la política en los estados. Fue el Barón de Humboldt el gestor de la geografía política y el fundador de la geografía moderna por los trabajos que realizó en sus diferentes viajes.

CARl Ritte sistematizó el pensamiento de Humboldt y extendió la influencia de los factores geográficos, no sólo sobre las plantas, los animales y el hombre, sino sobre las condiciones históricas. En su Geografía comparada, estableció un nuevo método para investigar las causas geográficas de la actividad humana. En contacto con las ciencias naturales, fue el primero que descubrió a la tierra como una fuerza viva y dinámica: la geografía es la ciencia del globo viviente. Sus alumnos exageraron sus acciones hasta pretender sacar a la geografía de la ciencia natural y situarla como ciencia histórica.

El famoso economista y profesor de ciencia política FEDERICo List, fue el primero que lanzó la idea de los grandes espacios y la importancia del control de las comunicaciones de un Estado. También son muy importantes, los estudios del famoso naturalista inglés RoBert ChARLES DARwin que en su libro El origen de las especies, señaló que el espacio es importante para la reproducción y esparcimiento de determinadas especies. El francés Augusto Comte, creador de la filosofía positivista y de la sociología, abrió con su método experimental, el camino a los estudios geopolíticos, señalando como fuentes de las variaciones sociales, la raza, el clima y la acción política. Es posible que tales afirmaciones hayan sido el origen del determinismo geográfico, tan discutido desde su aparición ${ }^{43}$.

En nuestro recorrido histórico, aparece la Geopolítica de la modernidad. El actual proceso global de reestructuración del sistema económico internacional tiene dos proyecciones íntimamente relacionadas: la económica o tecnológica y la estratégica. Con ello se quiere decir que el conjunto de innovaciones que se originan en la evolución de una determinada lógica científico comercial, es asumido por una política global de confrontación pretendidamente final con el mundo excluido. "Esto

42 Palacios Mejía, Hugo, Introducción a la teoría del Estado. Editorial Temis. Bogotá, 1965, pág. 76.

43 Perpiñá y Grau, Román, Determinantes económico-políticos de los grandes espacios. Editorial Labor, S.A. ISBN.84-335-3329-0. Barcelona, España, 1973, pág. 85. 
provoca la existencia de una estructura científica y tecnológica que evoluciona y se desarrolla por medio de impulsos militares y económicos ${ }^{44}$ ".

Las discusiones realistas e idealistas sobre la geografía, causaron el desengaño de los académicos hasta el punto de congelarla y convertirla en una asignatura más de los programas escolares. Por fortuna, en nuestros tiempos, esta ciencia cobra gran importancia por su estrecha relación con las relaciones de poder y por su singular significado en la creación del espacio, hasta el punto de que la sociología reconozca que es imposible generar un nuevo espacio, sin crear una nueva socie$\operatorname{dad}^{45}$. "Una sociedad sólo se crea a partir de actividades que exigen la puesta en valor de un espacio natural preexistente ${ }^{46}$ ".

La conceptualización de la geografía como ciencia espacial que se basó anteriormente, en una visión absoluta del siglo XX, ha hecho hincapié en que el espacio sólo puede comprenderse en términos de los objetos y los procesos que lo forman o sea que el estudio de la geografía debe concentrarse en el espacio, pero la crítica humanística que se desarrolló en la segunda mitad del siglo, lo ha ligado a la teoría social.

La preocupación del existencialismo ${ }^{47}$ por los seres humanos, en situaciones particulares y por la individualidad, ofrece un foco potencial para nuevas investigaciones geográficas. Sin embargo, poca atención se ha prestado a esta posibilidad, debido al énfasis del existencialismo en el individuo y en la libertad y por ende, al rechazo de una ciencia social que se ocupe del establecimiento de las regularidades que rigen el comportamiento humano. Si en la antigüedad, la geografía se constituyó en teoría y práctica de la guerra, es justo que en el futuro se ocupe de la protección del medio ambiente, del ordenamiento territorial y del mejoramiento de la calidad de vida del hombre. El nuevo orden mundial presupone que la geopolítica actúe como herramienta eficaz en el manejo de las relaciones internas de cada Esta-

44 Ceresole, op. cit., 194.

45 Hasta cuando la geografía crítica se pronunció, el espacio se pensó simplemente como la parte de un territorio ocupado por el hombre. Era el viejo discurso euclidiano que ha sido superado y hoy el término no se concibe sin esa conexión hombre-entorno como elementos definidores del espacio. El determinismo geográfico causó daños a la geografía al considerar que el medio ambiente era el que marcaba el carácter de los pueblos. Así, quienes habían nacido en el desierto, estaban condenados a morirse de sed.

$46 \quad$ Ibíd., pág. 205.

47 El existencialismo, centro del trabajo filosófico del francés Jean-Paul Sartre, parte de la frase "la existencia precede a la esencia". Es el hombre quien elige, tiene la libertad para decidir y por ello está condenado a ser libre. Sartre explicó esta teoría en su ensayo El existencialismo es un humanismo, en el que defiende esta rama filosófica de una serie de reproches que se le han formulado. 
do, como expresión democrática de la acción política del ciudadano y en las relaciones internacionales, con absoluta independencia y sin temor a nuevas formas de colonialismo.

"Cuatro son los condicionantes básicos que hacen a la definición de una doctrina de defensa: la geografía, la política, la demografía y la tecnología. Como ninguna nación es igual a otra, en teoría deberían existir tantas doctrinas de defensa como naciones" ${ }^{48}$. El libro de Yves LACOSTE, La geografía: un arma para la guerra, publicado en Francia en 1976, es todo un tratado de conocimientos científicos que van desde la antropología hasta la ecología, pasando por supuesto, por la historia, la geografía física, la geografía humana, la geografía económica, la ciencia política, la estadística, la filosofía y el arte de la guerra.

Los Estados mayores fueron y siguen siendo los cuerpos asesores de los comandantes militares, especialistas por áreas definidas y encargados de manejar los asuntos estratégicos para el planeamiento de la guerra. Posteriormente los aparatos estatales y las multinacionales, han reforzado sus actividades mediante el empleo de estados mayores; ellos son los más interesados en la geografía, como fundamento ideológico para definir exitosamente los conflictos militares o para ejercer el más común y eterno tipo de guerra: la económica. La experiencia muestra que los Estados que siempre se interesaron por la geografía, hoy son potencias o han impedido que sobre su propio territorio se aniden ideologías y sistemas políticos con intereses expansionistas. Precisamente esta es la razón por la cual, hoy es posible hablar, por lo menos de ocho importantes escuelas geográficas: la alemana, la inglesa, la francesa, la norteamericana, la soviética, la italiana, la española y la brasilera ${ }^{49}$.

La excesiva práctica de la geografía en el campo ideológico, dio origen a fines del siglo XIX, a la aparición de otra geografía: la de los profesores. En forma inconsciente, el discurso ideológico de la geografía de los profesores "oculta la importancia estratégica de los razonamientos que afectan el espacio ${ }^{50}$ ". Se aleja totalmente de las prácticas políticas y militares y de las decisiones económicas, disimulando la eficacia del instrumento de poder que se constituye mediante los análisis espaciales.

Los estados mayores de los aparatos militares y estatales de las grandes potencias, así como de sus multinacionales por el contrario, aprovecharon la decadencia

\footnotetext{
48 Lacoste, op. cit., pág. 293.

49 Santos, Milton; De Souza, María; Silveira, María L. Territorio, globalización y fragmentación. Editorial Hucitec - Anpuer. (1996). Tercera edición. São Paulo, pág. 129.

50 Lacoste, op. cit., pág. 17.
} 
académica y continuaron produciendo cartografía especializada para fines estratégicos militares y comerciales. No es gratuita la presencia de grupos financieros y económicos en los países del Tercer Mundo, con el fin de aprovechar los inmensos mercados que ofrece el sector terciario de la economía. La estrategia y la táctica de los ejércitos requieren obligatoriamente de cartografía actualizada que facilite la utilización de los armamentos enmarcados en lo que se denomina tecnología de punta. Nunca los mapas podrán ser reemplazados y ese es uno de los elementos del poder que aporta la geografía.

El espacio es el factor que mayor influencia tiene en la vida de los Estados. Su interpretación es el fruto de la evolución misma de las ciencias geográficas y de las ciencias políticas, desde el concepto puramente descriptivo de los griegos, hasta las concepciones de RATZEL, KJELLEN y HAUSHOFER que creyeron encontrar en él, el eje de la geopolítica y que guiados por el culto exagerado a su significación, empujaron a Alemania hacia el expansionismo. Por ello, conviene ante todo, precisar el concepto y luego, explicar su dimensión y alcance geopolítico ${ }^{51}$.

El espacio como simple extensión, área superficial mensurable que ocupa cada objeto, según la teoría euclidiana, carece de sentido en geopolítica, puesto que esta ciencia se ocupa profundamente de su significado en cuanto comprende una comunidad políticamente organizada, con necesidades, problemas y aspiraciones comunes; es decir, el mundo circundante donde discurre históricamente la vida del Estado y se proyecta hasta cobrar alcances inconmensurables en lo político, económico y social, y varias dimensiones según se trate de territorio, mar, espacio aéreo, plataforma continental o subsuelo ${ }^{52}$. En esta forma, el espacio es el resultado de diversos interactuantes que hacen difícil construir sobre él, una rígida teoría. Quizá la extensión territorial como tal, conserve aún su valor estratégico en el ámbito potencial, auncuando las nuevas formas de energía y la cobertura de las comunicaciones tiendan a dejarla fuera de lugar.

La diferencia entre territorio y espacio consiste en que el primero, es una forma de espacialidad delimitada en términos políticos ${ }^{53}$ y el segundo, está acompañado

51 La geopolítica, junto con los principios racistas de Alfred Rosenberg, que preconizaban la superioridad de los nórdicos sobre los demás grupos étnicos de la humanidad, aportaron los fundamentos para justificar, preparar y poner en práctica las acciones de conquista del Tercer Reich. "Haushofer llegó a tener tal influencia oficial que se considera el inspirador de las ideas geopolíticas contenidas en el capítulo XIV de Mi lucha, la obra polémica de Adolfo Hitler".

52 IBÁÑ̃z SánCHEZ, op. cit., pág. 132.

53 SaGuín, op. cit., pág. 163. 
de la construcción social y las relaciones entre el hombre y su entorno ${ }^{54}$. "El espacio geográfico es el producto de una historia social y como tal, el resultado de una determinada estructura de poder y de un sistema de relaciones productivas ${ }^{55}$ ". HANZ WEIGERT afirma que "el hombre moderno debe comprender que el espacio es destino", por lo tanto, resulta útil clasificar a los Estados por su extensión en gigantes, grandes, medianos, pequeños y miniestados. Esta clasificación se vuelve problemática, cuando se trata de administrar los territorios estatales y se recurre al tema de la soberanía.

"Soberanía y territorio continúan siendo piezas clave del sistema internacional ${ }^{56}$. Pero se han reconstituido y parcialmente desplazado, hacia otras arenas institucionales fuera del Estado y fuera de los territorios nacionalizados ${ }^{57}$. En los tiempos actuales, la soberanía se ha descentralizado y el territorio parcialmente se ha desinstitucionalizado. La soberanía se mantiene como una estructura del sistema, pero ahora está localizada en múltiples arenas institucionales: los nuevos regímenes legales privados transnacionales, nuevas organizaciones supranacionales y varios códigos internacionales de derechos humanos ${ }^{58}$.

\section{CONCLUSIONES}

Al final de este corto análisis que cubre más de un siglo de discusiones, es oportuno dejar en firme algunos conceptos, porque el principal inconveniente que ha debido sortear la geopolítica, es su interpretación. Puede decirse que existieron y existen diferentes corrientes sobre la ciencia que algunos han denominado "maldita" y sus relaciones con la geografía política, pero por fortuna, el panorama de hoy es claro y posibilita resumir esas ideas en cuatro visiones principales:

54 La territorialidad fue la característica fundamental del Estado, puesto que representaba su autoidentificación como superficie rodeada de una frontera defensiva y como ente capaz de asegurar la protección de sus súbditos. Ante el desarrollo de armas nucleares, la territorialidad se ha vuelto mucho más permeable y ha hecho más caduca la noción de Estado nacional.

55 Cerersole, op. cit., pág. 201.

56 Sanguín, op. cit., pág. 52.

57 En términos político-territoriales, la nación se caracteriza como el espacio homogéneo en donde hombres y mujeres hablan generalmente la misma lengua, pertenecen a una misma etnia, profesan eventualmente una religión común, comparten la misma cultura y el mismo patrimonio histórico y cultivan la misma civilización.

58 NoGue, op. cit., pág. 274. 
1. La geopolítica es dinámica, como un atleta en competencia, mientras la geografía política es estática, como la pista atlética sobre la cual se realiza la competencia. Esta fue una de las primeras interpretaciones de los geopolíticos anteriores a la II Guerra Mundial. Según ellos, la geopolítica es una nueva ciencia, técnica o arte que se ocuparía de la política a nivel geográfico, pero con un trato diferente de la geografía y dedicada principalmente a la acción y al poder.

Los geopolíticos de principios del siglo pasado, aseguraron que estaban construyendo otro saber, que en la realidad, sería más que una ciencia, un instrumento imprescindible para la estrategia, es decir, para la actuación político espacial del Estado. Como podemos observar, fue una visión adecuada en su momento histórico y no podemos olvidar que el mundo en la primera década del siglo $\mathrm{XX}$, antes de la Gran Guerra, vivía un orden multipolar conflictivo, con una situación de guerra latente entre las grandes potencias mundiales, lo cual legitimaba las acciones de quienes hacían geopolítica en aquel entonces.

2. La geopolítica es ideológica y por esta característica, llegó a considerarse como un instrumento del nazi fascismo o de los estados totalitarios, mientras la geografía política es una ciencia. Esta fue la interpretación de algunos geógrafos en los años 1930 y 1940, por ejemplo: A Tener y Leo WAibel, además de un buen número de científicos sociales de la posguerra ${ }^{59}$. Un nombre muy representativo de esta visión, fue PIERRE GEORge, tal vez el geógrafo francés más conocido entre los años cincuenta a setenta del siglo XX, que afirmaba que la geopolítica es una pseudociencia, una caricatura de la geografía política.

3. La geopolítica es la verdadera o fundamental geografía. Esta fue la interpretación que el francés Yves LACOSTE inauguró con su famoso libro La geografía: un arma para la guerra en 1976, y que sirvió como ideario para la revista Heródote, suplemento de geografía y de geopolítica muy destacado en la época ${ }^{60}$. En esa visión, la geografía de verdad, la esencial o fundamental, no habría surgido en el siglo XIX con Humboldt y Ritte, sino en la antigüedad, durante la aparición de los primeros mapas. De esta manera, lo que surgió en el siglo XIX, fue apenas la geografía de los profesores, la geografía académica, la que estaría preocupada básicamente por esconder o encubrir, con una cortina de humo, la importancia estratégica de la verdadera geografía, de la geopolítica en concreto.

La geopolítica o geografía de los Estados mayores o geografía fundamental, existió desde la antigüedad en la estrategia espacial de las ciudades-Estado de AlE-

\footnotetext{
$59 \quad$ Vivó, op. cit., pág. 13

${ }_{60}$ Lacoste, op. cit., pág. 3.
} 
JANDRO el Grande, por ejemplo o a partir de los escritos de HERÓDOTO como la Geografía fundamental, autor y obra que en una lectura sesgada, representaron el imperialismo ateniense ${ }^{61}$.

4. La geopolítica actual se presenta como un área o campo de estudios interdisciplinar. Esta interpretación empezó a predominar a partir del final de los años 1980, y es casi un consenso en los días actuales. No se trata tanto de lo que ha sido la geopolítica y sí de lo que representa en la actualidad. En consecuencia, si buscamos quién inició la geopolítica, entre los hombres que contribuyeron a desarrollarla, seguramente concluiremos que ninguno de ellos provenía de un área única de conocimiento: hubo juristas, como KJELLÉn; geógrafos como MACKINDER; militares como MAHAN y HAUSHOFER, y otros especialistas. Es un hecho que en la actualidad, la geopolítica se encuentra en manos de los economistas y hombres de negocios. Pero lo más importante, es que la geopolítica se encuentra más viva que nunca y camina de la mano de quienes en el siglo XXI, continúan con la intención de refundar imperios.

Para finalizar, quiero expresar especial agradecimiento a la Dirección General de Estudios de Posgrado y al Instituto de Geografía de la Universidad Nacional Autónoma de México, entidades que han hecho posible la publicación de este artículo y que patrocinan mi formación doctoral como becario permanente. 


\section{BIBLIOGRAFÍA}

CAstLes, M. y Kovack, G. Revolución tecnológica y reestructuración económico- política del sistema mundial. Impactos de la tecnología avanzada sobre el concepto de seguridad. Madrid: Frepi, 1978, 198 pp.

Ceresole, Norberto. Política nacional y proyecto de país. En un mundo apolar. Buenos Aires: El bloque, 1993, $362 \mathrm{pp}$.

Ceresole, Norberto. Tecnología militar y estrategia nacional. Política y economía de la defensa. Buenos Aires: Pleamar, 1991, 223 pp.

Сномккі, Noam. La nueva estrategia militar de Estados Unidos. En: Geopolítica del caos. Le Monde Diplomatique. Edición española. Barcelona: Debate, 1999, 338 pp.

Dorpalen, ANDREAs. The world of general Haushofer. New York: 1942, 234 pp.

García Negrete, Jorge. Esquema para una investigación geopolítica. En: Revista Geográfica, 4. Quito: Instituto Militar Geográfico, 1989, 198 pp.

GonZÁlez Posse, ERnesto. La frontera como factor de integración. Buenos Aires: Intal, 1990, 230 pp.

GeorCe de LA, PAUL-MARIE. El papel de la onu, ocupado por la otan. Organizaciones internacionales, alianzas y caos geopolítico: ¿debatir el papel de la oNU? En: Geopolítica del caos. Le Monde Diplomatique. Edición española. Prólogo de Manuel VázQuez Montalbán. Madrid: Debate, 1999, 365 pp.

Gregory, Derek, Martín, Ron y Smith, Graham. Geography. Society, space and social science. Saint Paul: University of Minnesota Press, 1994, 403 pp.

IBÁÑez SÁnchez, José Roberto. Democracia, seguridad y fuerza pública. Santafé de Bogotá: Fuerzas Militares, 1994, 416 pp.

- Teoría del Estado - Geopolítica y geoestrategia. Colección de Oro del Militar Colombiano, vol. XVII. Bogotá: Fuerzas Militares, 1985, 188 pp.

Lacoste, Yves. La geografía: un arma para la guerra. Barcelona: Anagrama, 1977, 198 pp.

Londoño Paredes, Julio. Los fundamentos de la geopolítica. Colección de Oro del Militar Colombiano, vol. IX. Bogotá: Fuerzas Militares, 1978, 209 pp.

López Trigal, Lorenzo y Del Pozo Paz, Benito. Geografía política. Madrid: Cátedra, 1999, 334 pp.

LuCbert, MAnuel. Geopolítica de Asia Central: India como centro. Cap. 8 Introducción. En: Geopolítica del caos. Le Monde Diplomatique. Edición española. Prólogo de Manuel Vázquez Montalbán. Madrid: Debate, 1999, 456 pp.

MACKINDER, HALFORD. The geographical pivot of history. Londres: The Royal Goegraphical Society, 1944, 767 pp.

Nogué, Foni y Rufí, JoAn. Geopolítica, identidad y globalización. Madrid: Ariel, 2001, 235 pp.

OSLENDER, ULRICH. Espacializando resistencia: perspectivas de 'espacio'y 'lugar' en las investigaciones de los movimientos sociales. En: Cuadernos de Geografía, vol. VIII, 1. Santafé de Bogotá: 1999, 445 pp.

Palacios Mejía, Hugo. Introducción a la teoría del Estado. Bogotá: Temis, 1965, 330 pp.

PAinter, Joe. Lecturas en geografía. En: Política, geografía y geografía política. Traductor, Ovidio Delgado Mahecha. Santafé de Bogotá: Universidad Nacional, Departamento de GeografíaFacultad de Ciencias Humanas, 1998, 445 pp.

Perpiñá y Grau, Román. Determinantes económico-políticos de los grandes espacios. Barcelona: Labor, 1973, 189 pp.

SÁncheZ, JoAn-Eugeni. Geografía política. Espacios y sociedades. Madrid: Síntesis, 1999, 330 pp. 
SAnguin, André-Luis. Geografía política. Elementos de geografía. Barcelona: Oikos-tau, 1981, $181 \mathrm{pp}$.

SMall, Gretchen y SMall, Dennos. El complot para aniquilar a las fuerzas armadas y a las naciones de Iberoamérica. Resumen Ejecutivo. Washington: 1997.

Santos, Milton, De Souza, María y Silveira, María L. Territorio, globalización y fragmentación, 3 ed. Sao Paulo: Hucitec-Anpuer, 1996, 236 pp.

Strausz-Hupe. Geopolítica. Nueva York: 1942, 254 pp.

TAYLOR, PETER J. Geografía política - Economía-mundo, Estado-nación y localidad. Madrid: Trama, 1994, 339 pp.

Tzu, Sun. El arte de la guerra de Wu Sun, 3 ed. Santafé de Bogotá: Tercer Mundo, 1997, 98 pp.

Unwin, Tim. El lugar de la geografía. Traductora, Jerónima García Bonafé. Madrid: Cátedra, 1995, 278 pp.

Young, Oran. Sistemas de ciencia política, 3 ed. México: Fondo de Cultura Económica. 1993, 216 pp.

VÁSQUEZ SÁNCHEZ, JAIME. Estrategias geopolíticas y posibilidades para un nuevo ordenamiento territorial en el medio rural. En: Memorias XVI Congreso Colombiano de Geografía. Santiago de Cali: 2000, 453 pp.

Vivó, Jorge A. La geopolítica. En: Jornadas. México: Centro de Estudios Sociales-Colegio de México, 1943, 90 pp.

WORSLEY, METER. El tercer mundo. Una nueva fuerza vital en los asuntos internacionales. Traductor, Martí Soler. México: Siglo Veintiuno, 1973, 269 pp. 